\title{
A Novel Approach on the Advancement in Polymer Phase Change Material in Solar Energy
}

\author{
G. Jegan $\mathbb{D}^{1},{ }^{1}$ P. Ramani $\left(\mathbb{D},{ }^{2}\right.$ T. J. Nagalakshmi ${ }^{(D)},{ }^{3}$ S. Chitra $\mathbb{D}^{4},{ }^{4}$ and T. Samraj Lawrence $\mathbb{D}^{5}$ \\ ${ }^{1}$ Department of Electronics and Communication Engineering, Sathyabama Institute of Science and Technology, Chennai, \\ Tamil Nadu, India \\ ${ }^{2}$ Department of Electronics and Communication Engineering, SRM Institute of Science and Technology, Ramapuram, Chennai, \\ Tamil Nadu, India \\ ${ }^{3}$ Department of Electronics and Communication Engineering, Saveetha School of Engineering, Saveetha Institute of Medical and \\ Technical Sciences, Chennai, 602105 Tamil Nadu, India \\ ${ }^{4}$ Department of Electronics and Communication Engineering, Rajalakshmi Engineering College, Chennai, Tamil Nadu, India \\ ${ }^{5}$ Department of Information Technology, College of Engineering and Technology, Dambi Dollo University, Dambi Dollo, \\ Oromia Region, Ethiopia
}

Correspondence should be addressed to G. Jegan; gjegan.ece@sathyabama.ac.in and T. Samraj Lawrence; samraj@dadu.edu.et Received 5 November 2021; Accepted 7 December 2021; Published 10 January 2022

Academic Editor: V. Mohanavel

Copyright (c) 2022 G. Jegan et al. This is an open access article distributed under the Creative Commons Attribution License, which permits unrestricted use, distribution, and reproduction in any medium, provided the original work is properly cited.

A wide interest has been shown in the application of solar energy in recent times. This motivated the researchers to make a development in the approach of solar energy, but there are different technologies like MPPT, CPG, and grid mode that have been used to maintain a constant temperature. Among these, phase change material has been used to regulate the temperature in the system. Solar energy is becoming an essential approach for increasing the efficiency of thermal energy conversion and utilizing polymeric step change composites, which have attracted extremely large interest in recent years due to their advantages of high energy density and powerful energy output stability. A plethora of reviews and reports have been published to compile the diverse range of PCMs made available for various applications. PCMs are created by improving thermophysical thermodynamic stability, latent heat, and heat capacity. Furthermore, the possible applications of polymer phase PCMs in a variety of fields, such as energy storage devices, thermal corrective action, and temperature-controlled drug carriers, are detailed. In this paper, a novel approach on the advancement of nanoconfined phase change material is defined along with the application of the solar energy system.

\section{Introduction}

The major issues that were faced in the world are environmental problems and the energy crisis, and this has to be addressed. The fuel price increases when there is a continuous rise in the power consumption level, and the main driving force of the emission of greenhouse gas is the effective use of renewable energy sources. Consumption of electricity increased by 1.5 percent globally in 2018 compared to 2017 [1]. Many studies have been undertaken on global power usage and production, and these topics have been extensively addressed. The consumption of renewable energy has become one of the answers to greenhouse emissions, and as a result, sustainable energy programs have been adopted in many areas. Professional possibilities include rapid commercial improvement for the advancement of societies around the world, which results in a rapidly rising energy consumption. The majority of power usage used coal and oil which are finite and cause significant carbon pollution.

As a result, efficient energy consumption has become a key concern, prompting a shift in the tendency towards the use of solar and wind resources. Energy production, for example, is unlimited, long-term available, readily available, and ecologically acceptable, making it a useful replacement 
to coal and oil [2]. Heat transfer is more efficient than latent heat storage because it gives a significantly higher efficiency with a smaller temperature gradient while absorbing and releasing energy. Thermo-chemical, sensitive, and heating value storage is all types of TES that use the shift of stored energy inside the storage devices. Thermal energy storage (TES) is a viable way to solve this issue, and it is currently being developed at a rapid pace. The adoption of TES enhances the general performance and greatest degree possible of renewable energy power-producing applications [3].

The impacts of convective heat transfer during the phase separation of petroleum ether in a plate heat exchanger were experimentally studied. The dissolving front is developed at different periods near the HTF (heat transfer fluid) pipe and moved at varying rates outside, toward the shell, according to the researchers. They discovered that changing the inlet temperature of water from $70^{\circ} \mathrm{C}$ to $80^{\circ} \mathrm{C}$ closes out thermal decomposition time by $37 \%$. The phase transition and crystallization of a wax in a shell and tube heat exchanger with HTF cycling within the tubes and PCM overlaying the shell side were investigated for various performance parameters and device characteristics.

When fossil fuels are used for energy, undesired chemicals are released into the atmosphere, resulting in increased fossil fuel emissions [4]. The long-term viability of energy production is jeopardized due to lack of resources and permanent fossil-fuel combustion. To address the concerns of rapidly rising consumption of nonrenewable fossil fuels and rising emissions while also ensuring the survival of life on earth, the researchers are working to develop new power generation, transformation, and storage systems. Because of changeable power production, environmental procedures, and large amounts of energy stores, regenerative techniques of energy storage applications have gotten a lot of interest in this area. Solar, wind, mechanical, hydrothermal, and other renewable resources are being used to replace traditional oil and coal sources of power [5]. Considering the lack of radiation from the sun during the nighttime and mother nature's transmission losses, the effectiveness of solar energy consumption is heavily reliant on the energy storage mechanism. Power in many kinds, such as wiring, robotic, and solar energy, can be maintained in a variety of ways.

Pumped hydropower storage (PHPS), flywheels, and storage systems can all be used to store mechanical energy (CAES). PHPS and CAES are the best pneumatic and hydraulic systems for large-scale facilities; nevertheless, flywheel energy can be employed for limitations or restrictions. This stored energy can be employed when the grid's power source is unavailable [6]. Thermal energy is then stored in a variety of ways, including heating, latent heat, thermochemical energy, or a mixture of these. Sensible radiant heat storing is a type of TES which shows the significant changes in heating between charging and discharging operations. Sensible radiant heat retention is a type of TES which shows the significant changes in thermostat between charging and discharging operations. The specific heat is an indicator of the amount of heat stored as a result of the accumulation of substance and temperature variations. PCM characterization for better usage in SWHs, establishment of a novel
SWH that can be combined with the PCMs, long-term evaluation of the performance, and standardization of the SWHs for sale are all technical challenges [7]. It is worth noting that the economic viability includes expenditure analyses in various areas across the world, as well as the provision of subsidies, particularly in nations with plentiful solar radiation.

\section{Literature Review}

The crystallization operations of wax RT35 as phase transition materials in a finned tube are investigated in an experimental study. As a result, the impact of utilizing fins in this study, as well as several operational characteristics, is taken into account. The goal of this research is to design and build a unique shipping container that will be compared to a finless heat transfer. The effect of changing the inlet pressure and temperature rate on the charging and discharging processes of the exchanger is investigated in a series of experiments. It has been demonstrated that utilizing fins in the phase transition process improves the crystallization processes. This is defined as the investigation of phase change inside a finned-tube heat exchanger experiment proposed by [8]. The tendency of this fluctuation is various for heat pumps; for the bare tubular heat exchanger, boosting the temperature difference more efficiently reduces melting time.

The test of a phase change material in thermal performance is proposed by [9] with the cool roof system by a scaled model. Cool roofs in general are excellent at reducing thermal loads, but they have an issue with rising heating load. As a result, the purpose of this research is to use phase change features of phase change material to compensate for the shortcomings of the cool roof system (PCM). The investigation was conducted to verify the heat transfer performance of the PCM cool roof structure by monitoring the temperature on the horizontal and vertical of a tiny model $(666 \mathrm{~mm})$ [10]. PCM was added and not introduced, and the surface temperature between the cream-colored finish colors was evaluated. As a result, the degree of the surface of the plate when using PCM was lower than that when not using PCM, and there was a temporal lag in heat growth. When comparing temperature distributions based on finish color (brown vs. white), white demonstrated a low temperature profile of up to $16.35^{\circ} \mathrm{C}$. White had a lower thermal performance of $5.40^{\circ} \mathrm{C}$ than brown even at ambient temperature. The employment of the PCM cool roof structure in roofing finishes might reduce the temperature rise and keep the interior temperature low.

There are different methods involved in the solar cells, and [11] proposed a method on recent advances in dyesensitized solar cells. Energy production is a plentiful and freely obtainable renewable resource on the planet, and numerous types of photovoltaic (PV) devices, such as organic, inorganic, and hybrid cells, have been produced to harness it. Photovoltaic modules transform solar radiation to electricity without causing environmental harm. Despite the fact that hydrogel solar cells (inorganic cells) are normally strong and good, they are inflexible and expensive to manufacture. To circumvent these drawbacks, researchers 
have concentrated on organic solar cells. The performance of DSSCs, which are made up of a sensitized transistor (photoelectrode) and a catalytic cathode (counter electrode) with a solution sandwiched across them, is determined by a variety of parameters. DSSCs have achieved a maximum electrical conversion efficiency of 11.1 percent so far, which would still be low for industrial use. The working concept, factors impacting performance, and main issues confronting DSSCs are all examined in this paper.

The environmental protection of the solar energy is proposed by [12]. People consumption of energy resource distribution has always been a core matter of all living beings, and attempting to obtain one immortal source of power has long been a human goal. Researchers and experts feel that using pure energies such as photovoltaic, turbine, and thermal ground energy, among others, rather than oil and coal technologies, will obstruct conservation efforts. In this way and around two decades after the introduction of the Photo voltaic cell into the public arena of producing energy, the close bond between strategy and resource utilization has led to the conclusion that there really is no place for financially explaining arguments and searching for ways to use sun's radiation and generated power.

An experiment study on the performance of a novel solar water heating system is proposed by [13] with and without PCM. By utilizing phase change materials (PCMs) for heat storage and inserted oscillation heat pipe (OHP) for improving performance, a unique solar water heating system (SWHS) effective in decreasing the influence of radiation from the sun intensity changes has been fabricated. Depending on the strength of solar irradiance in changing seasons and climate circumstances, several working styles can be chosen. A testing machine has also been built to evaluate the study's validity. For a few years in a row, full-year measurements in a variety of environmental situations have been taken out in Nanjing, China [14]. The performance of the system was tested and compared between the systems with and without PCM, including collecting efficiency (CE), mean collecting effectiveness (ACE), coefficient of performance (COP), and exit water temperature (EWT). Under comparable system parameters, the device with PCM is shown to perform significantly better. CE variation with PCM is over 30\% lower during the day than that without PCM. EWT with PCM may maintain a temperature of above $50^{\circ} \mathrm{C}$ at night in the summer, whereas EWT without PCM has a noticeable drop. At night in the winter, COP with PCM is greater than 3.0, allowing EWT to reach $50^{\circ} \mathrm{C}$ in a substantially lesser duration than that without PCM.

\section{Methodology}

The research is about generating the power from the solar energy using the phase change material (PCM). Most of the research uses the CGPT and MPPT to generate the power from the solar energy, but they have several issues involved in generating the solar power; among these, the main issue is regulating the power. So, to overcome this issue, different research studies were developed; among these, PCM plays an important role in regulating the tem- perature. In this research, the advancement in the PCM method is used to regulate the temperature; hence, the power could be generated and used for the different purposes. Overview of PCM and power generation from the solar system is discussed in this section.

3.1. Advance Phase Change Material. Phase change material has expanded more interest over the research, and this produces the importance of the energy. The following is one of the categories, types, and approaches that will be covered. PCMs are divided into four main categories based on their phase transition: solid-liquid, solid-solid, liquid-gas, and solid-gas [15]. Solid-liquid PCMs are the best for storing heat energy between these four types, and they come in inorganic and eutectic forms, as illustrated in Figure 1.

Although it may be employed at a wide variety of climates and has a strong melting temperature, wax counts as a PCM. Paraffin can also be frozen without having to be supercooled. As a result, the most expensive, practical, and extensively utilized PCM is thermoset paraffin wax. Fatty acids are capable of replicating melting and being frozen with no or little crystallization [9]. The expense of saturated fats, which can be 2.0 to 2.5 twice those of petroleum ether, is one factor that prevents them from being used, since their heavy metals have not been a viable contender for PCM. Nevertheless, due to their strong heat conductivity and latent heat of reaction per cubic meter, metals are plausible rivals when quantity is considered.

Organic compounds, in their broadest sense, refer to any material found in nature. The majority of organic materials have carbon-hydrogen bond mixtures that are associated with living organisms. There are two types of organic PCMs: petroleum and nonparaffin. Organic compounds have a constant freezing characteristic, which means they may melt and freeze repeatedly without losing their hidden melting temperature. They are also highly stable, self-nucleating, and generally reusable.

Thermal properties of different kinds of organic and inorganic materials are listed in Table 1 . The beneficial attributes and characteristics of the selected materials are as follows. However, the low thermal conductivity of organic PCMs in a solid form and the significant thermal expansion necessary during the solidification stage are disadvantages. The bulk thermal energy storage capacity of organic PCMs is poor; however, the flammable condition can generally be avoided by the well design. The paraffin fabrication process [16], on the other hand, is extremely costly [17]. Another disadvantage is that the manufacturers use paraffins, which are a structured paraffin mix that may be rather costly.

3.2. Solar Energy Production Using PCM. The solar energy is the most popular source which has been used in the household, and this offers certain benefits and annual investments. There are different types of solar energy such as photovoltaic, solar thermal, and solar organic system. In this study, the generation of power involves the use of phase change material (PCM) to store energy and regulate the temperature. Due to the potential of dispatchability, they are used on great demand, making them more competent and cost- 


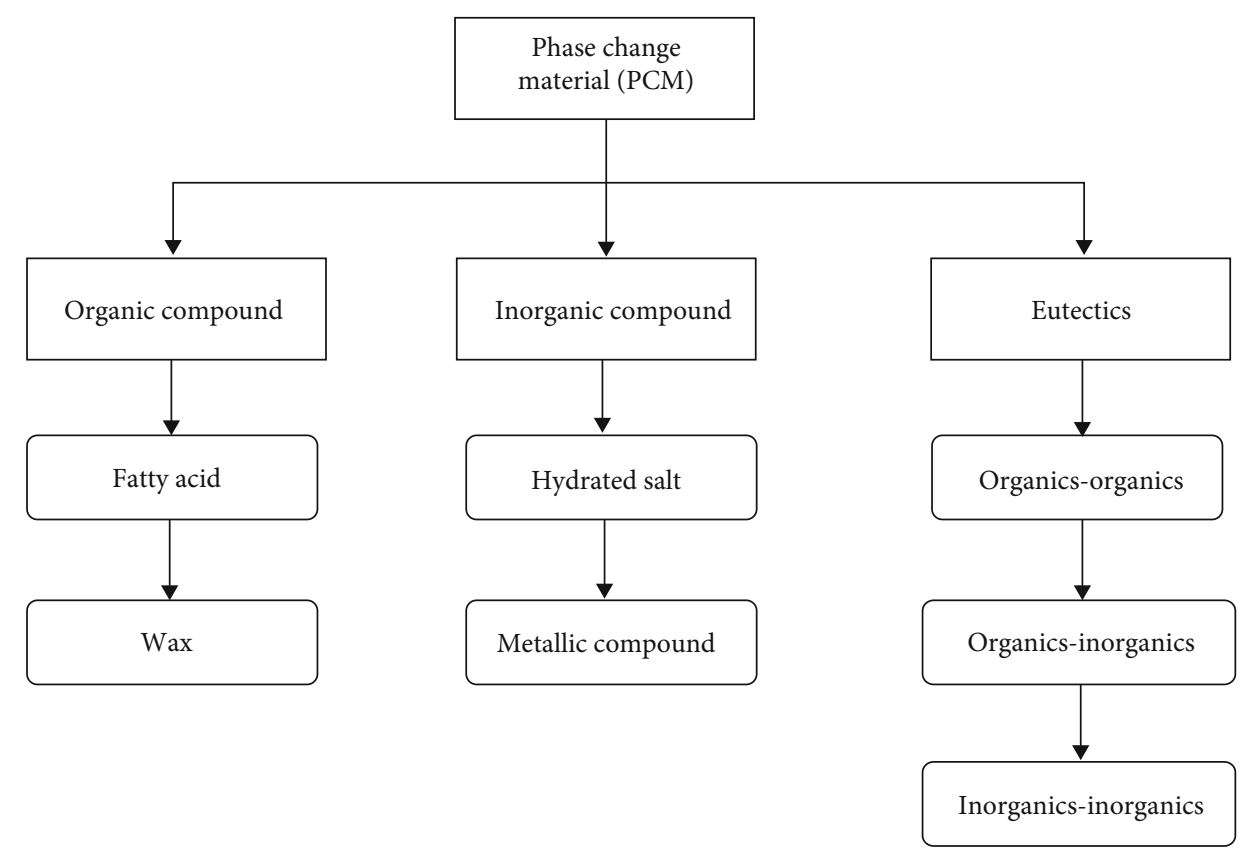

FIgURE 1: Classification of phase change material.

TABLE 1: Thermal properties of different kinds of organic and inorganic material.

\begin{tabular}{|c|c|c|c|c|c|}
\hline Composition of heat storage & Composition type & Melting point $\left({ }^{\circ} \mathrm{C}\right)$ & Sensible heat & Heat conductivity & Density solid \\
\hline Acetamide & Chemical compound & 83 & 2.5 & - & 1.159 \\
\hline Acetanilide & Chemical compound & 119 & 2.00 & - & - \\
\hline Erythrol & Chemical compound & 117 & 1.38 & 1.49 & 1.48 \\
\hline Trimethylolethane & Mixture & 30 & 2.75 & 0.66 & 1.12 \\
\hline $\mathrm{Na}_{2} \mathrm{~S}_{2} \mathrm{O}_{3} \cdot 5 \mathrm{H}_{2} \mathrm{O}$ & Hydrated salt & 49 & 3.83 & - & - \\
\hline
\end{tabular}

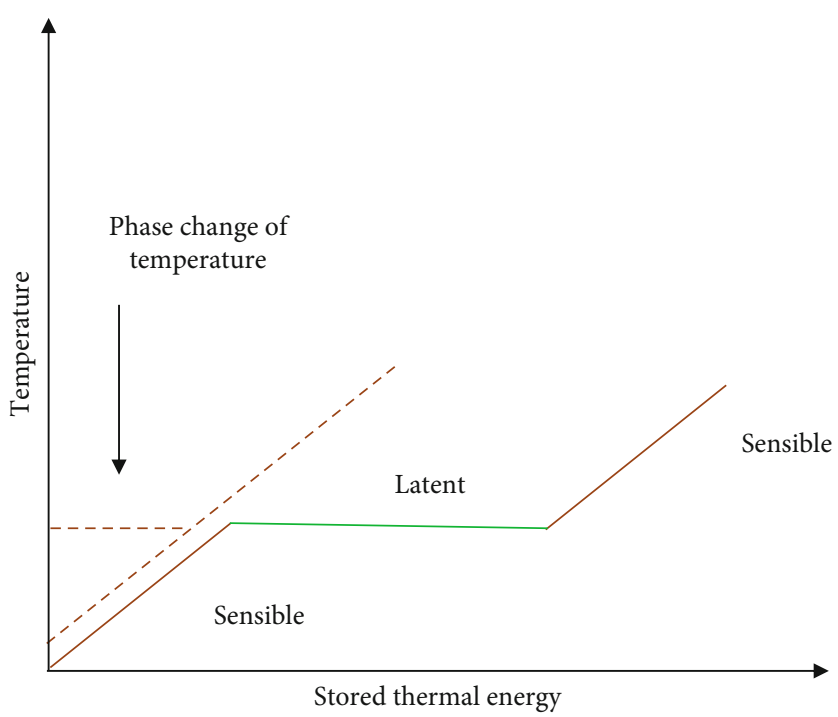

FIgURE 2: Measurement of increased thermal energy. 


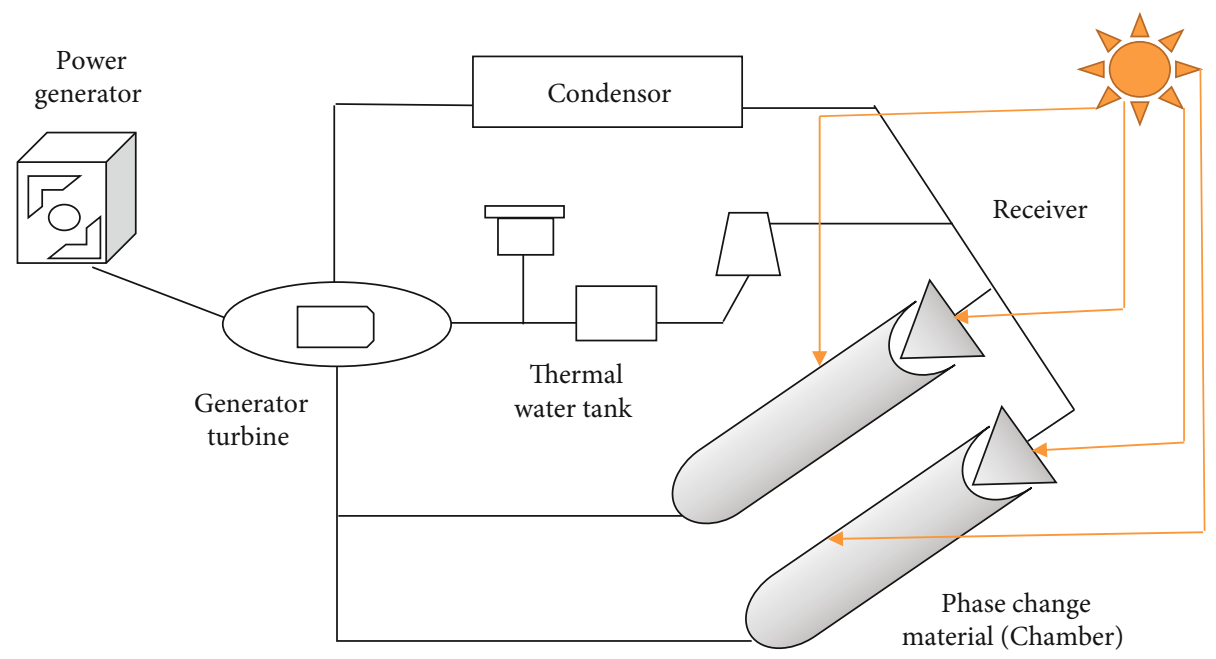

Figure 3: Schematic thermal energy storage using PCM.

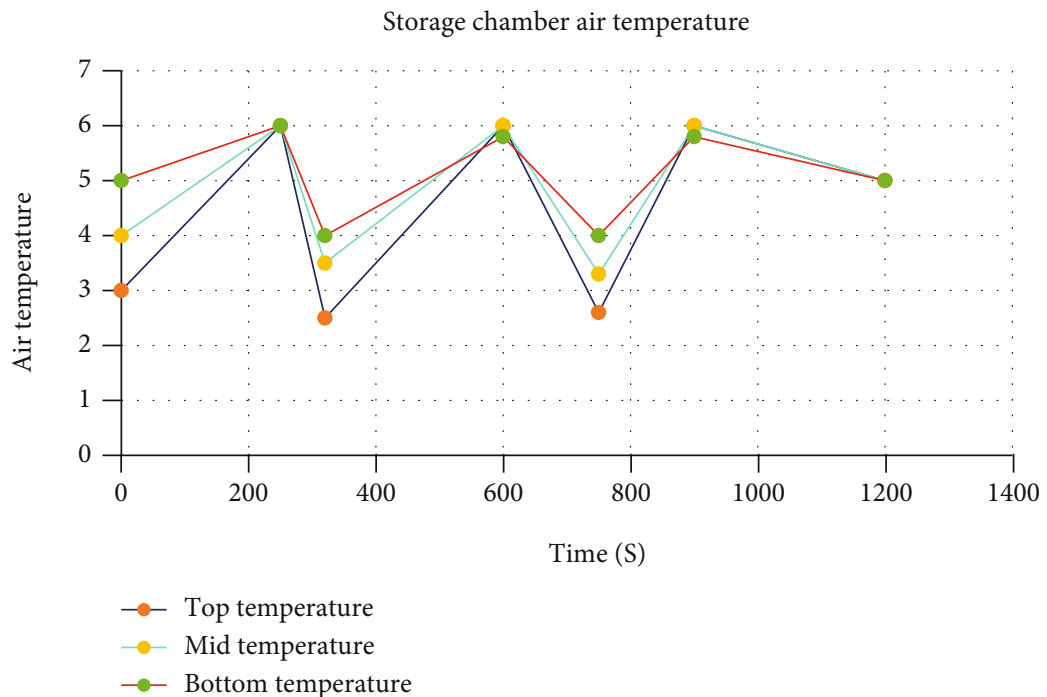

FIGURE 4: Storage chamber air temperature.

effective. Increased thermal energy storage (TES) systems are shown in Figure 2. Thermal energy, on the other hand, has not been proven safe; just a few generating facilities throughout the world have now been recognized as testing this method [18]. More modern SEGS prototypes have always used costly liquid fuel as a backup system, resulting in a temperature increase from 300 to $400^{\circ} \mathrm{C}$; nonetheless, the technique is still financially unfeasible.

Phase change material is one type of heat trapping material utilized in solar energy generating system. Phase change material has not yet attained the desired economic level or substantial use due to the thermal conduction, which requires a long power conversion period, despite the fact that it presents a tremendous possibility to help the lowering of cost of power supplied by SEGS [6]. By adopting single-stage PCM storage, the heat exchange methodology for single-stage phase change material of various PCM salts may be studied. The findings demonstrated that PCMs are theoretically capable of achieving the necessary objectives, and they proposed a phase change material memory design with a vertically stacked heat pipe mentioned in Figure 3.

The interplay involving PCMs and the heat transfer fluid during charging and discharging is the most important part of utilizing latent heat storage in a highly focused solar thermal system. The CST plant could also be linked to a supercritical carbon cycle (s-CO2), in which it can be coupled to the Brayton cycle for energy production, and this works with thermal storage and the Rankine cycle [19]. A reflector field, center block (solar receiver), heat storage system, and energy block are all part of the political process. Reflector fields capture and focus sun power on the solar receiver. The heat transfer then circulates the heat generated through the process to a power block, where it is converted from heat to electric power. Thus, the solar energy is converted to power using the phase change material. 


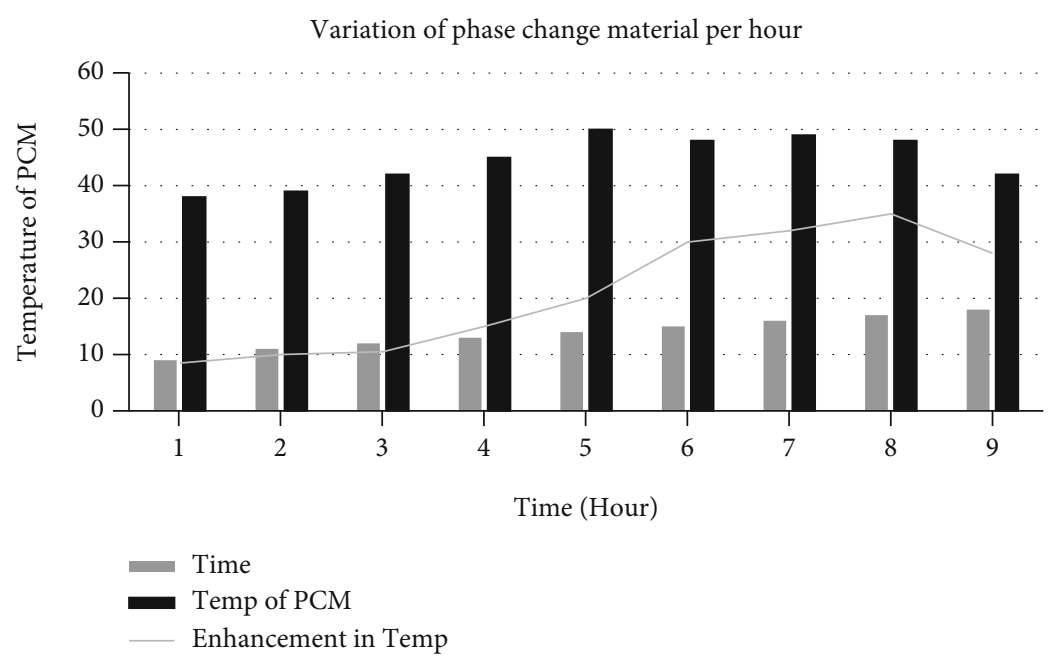

FIGURE 5: Variation of phase change material per hour.

TABLE 2: Comparison of PCM dealing in different sectors.

\begin{tabular}{lcc}
\hline Set & Ratio & Sector \\
\hline 1 & $18 \%$ & PCM new development \\
2 & $21.5 \%$ & Treatment of existing PCM \\
3 & $15 \%$ & Specific application and technologies using phase change material \\
4 & $30 \%$ & Thermal properties of existing PCM and their studies \\
5 & $13 \%$ & Integration of PCM into building components \\
\hline
\end{tabular}

3.3. Application of PCM. Many applications for thermal storage have been developed using phase transition materials. PCM was housed in an aluminum box with a specific photovoltaic reflective coating on the front face to reflect a PV cell attached to the front [20]. The PCM was used in a carbon black to improve radiant heat evacuated by increasing heat capacity, and its model was evaluated to air spring blow chilling using a cold Li-particle batteries. Rising operating temperatures impact the efficiency of constructing photovoltaic devices as a source of electricity (BIPV). While their usefulness is limited by their reduced temperature conductivity and high crystallization separation during crystallization, PCMs can be utilized to actively restrict this temperature increase.

\section{Result and Discussion}

The following section shows the result obtained based on the conversion of solar energy to electric power using phase change material.

4.1. Selection of Phase Change Material. The limit of atmospheric temperature inside the cold storage area is acquired from the chart of temperatures against time for PCM selection.

The PCM is then chosen based on its melting point, which should be inside the air range of temperature, and this is shown in Figure 4. Figure 5 shows the temperature varia-

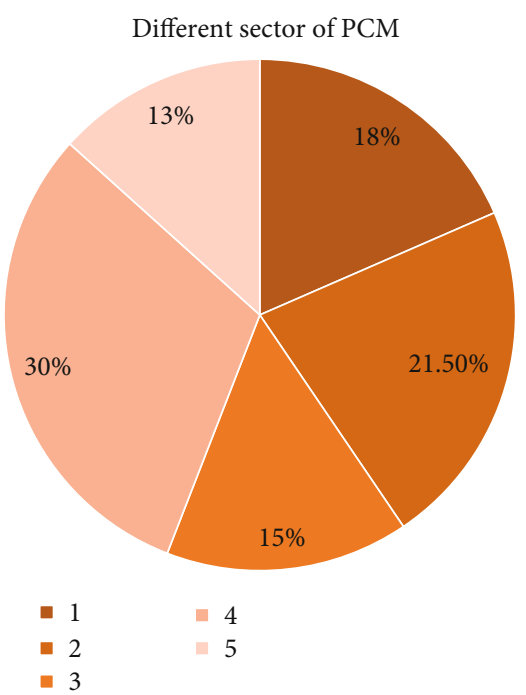

FIgUre 6: Comparison of PCM dealing in different sectors.

tions in the PCM as well as an enhancement in the heat of the phase change material.

In each case, the average PCM temperatures per day were 41.10 and 48.10 degrees Celsius, respectively. Temperature increased by $17.1 \%$ according to the PCM. It has an ability to absorb heat quickly during sunrise hours and release the heat during sun set hours, and it outperforms CTSS and TSS in every way. This is noted based on Figure 5. 


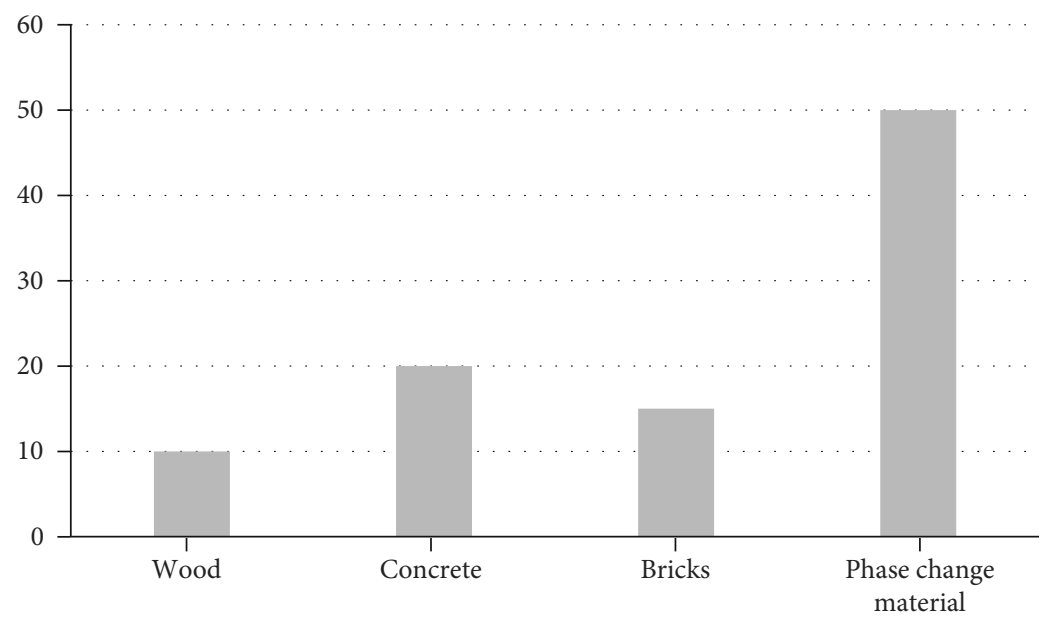

Figure 7: Density of energy storage.

4.2. Comparison of PCM Dealing in Different Sectors. The proportion of energy consumed in the building industry is utilized to power active heating and ventilation systems for interior air $[21,22]$.

Because the study themes in the literature include all aspects of phase change thermal applications, it is difficult to keep track of what is new, because some new findings may contradict old ones. Nonetheless, Table 2 and Figure 6 might provide an overview of the topics related to PCM in the industry.

4.3. Energy Consumption. Perishable food, medications, and pharmaceuticals are transported and stored. Building envelopes are more than just buildings; they do provide shelter from the elements while being sensitive to the cultural weather conditions, due to its considerably more heat transfer interaction and more straightforward application.

As shown in Figure 7, the building envelope is among the most researched parts of study and control, and it also offers a great possibility for energy reduction and the demand. It allows for the control of energy expenses and the enhancement of energy consumption, as well as economic and environmental effect.

\section{Conclusion}

A descriptive examination of the many technological solutions utilized in the modelling of PCM integration systems in building envelopes, as well as the simulation tools employed in this technique, is included in this paper. The researchers followed the technological methodologies utilized in solar energy storage system simulation. The study dedicated to the utilization of these approaches and methodologies in the application of solar management system techniques is continually growing, owing to the resource's potential, which has become an economic concern. Indeed, the retention of electrical energy using appropriate kinds of PCM is a continuing issue for building designers, and it has the potential to play a significant part in the upcoming power system. PCM has an efficiency of power absorption that is greater than that in other circumstances, making it the most effective in this situation. In the case of a onehour power outage, PCM absorbs more energy than the others. When PCM absorbs energy at a faster pace, more power is saved; hence, in a 1-hour power outage, more energy is saved than in any other condition.

\section{Data Availability}

The data used to support the findings of this study are included within the article.

\section{Conflicts of Interest}

The authors declare that there is no conflict of interest regarding the publication of this article.

\section{Acknowledgments}

The authors would like to express their gratitude towards Sathayabama Institute of Science and Technology for providing the necessary infrastructure to carry out this work successfully.

\section{References}

[1] E. Koutroulis, K. Kalaitzakis, and N. C. Voulgaris, "Development of a microcontroller-based, photovoltaic maximum power point tracking control system," IEEE Transactions on Power Electronics, vol. 16, no. 1, pp. 46-54, 2001.

[2] Y. E. Abu Eldahab, N. H. Saad, and A. Zekry, "Enhancing the maximum power point tracking techniques for photovoltaic systems," Renewable and Sustainable Energy Reviews, vol. 40, pp. 505-514, 2014.

[3] S. Sahoo, A. Gopalan, S. Ramesh et al., "Preparation of Polymeric Nanomaterials Using Emulsion Polymerization," Advances in Materials Science and Engineering, vol. 2021, Article ID 1539230, 9 pages, 2021.

[4] B. Subudhi and R. Pradhan, "A comparative study on maximum power point tracking techniques for photovoltaic power 
systems," IEEE Transactions on Sustainable Energy, vol. 4, no. 1, pp. 89-98, 2013.

[5] G. Edman Jonsson, H. Fredriksson, R. Sellappan, and D. Chakarov, "Nanostructures for enhanced light absorption in solar energy devices," International Journal of Photoenergy, vol. 2011, 11 pages, 2011.

[6] Nirmala, G. Ramkumar, S. Sahoo et al., "Artificial intelligence to analyze the performance of the ceramic-coated diesel engine using digital filter optimization," Advances in Materials Science and Engineering, vol. 2021, Article ID 7663348, 10 pages, 2021.

[7] P. D. Sonawane, V. Bupesh Raja, and M. Gupta, "Microstructure, mechanical, and electrical properties and corrosion analysis of lead-free solder CSI joints on $\mathrm{Cu}$ substrate using novel concentrated solar energy soldering (CSES) method," Advances in Materials Science and Engineering, vol. 2020, 16 pages, 2020.

[8] A. Váz Sá, R. Almeida, H. Sousa, and J. Delgado, "Numerical analysis of the energy improvement of plastering mortars with phase change materials," Advances in Materials Science and Engineering, vol. 2014, Article ID 582536, 12 pages, 2014.

[9] M. Rahimi, A. Ranjbar, D. Ganji, K. Sedighi, and M. Hosseini, "Experimental investigation of phase change inside a finnedtube heat exchanger," Journal of Engineering, vol. 2014, 11 pages, 2014.

[10] S. G. Yoon, Y. K. Yang, T. W. Kim, M. H. Chung, and J. C. Park, "Thermal performance test of a phase-change-material cool roof system by a scaled model," Advances in Civil Engineering, vol. 2018, Article ID 2646103, 11 pages, 2018.

[11] Y. Su, Y. Zhang, K. Lin et al., "Numerical study on resistance change characteristics of phase change materials," Advances in Materials Science and Engineering, vol. 2021, Article ID 7934173, 12 pages, 2021.

[12] U. Mehmood, S. Rahman, K. Harrabi, I. A. Hussein, and B. Reddy, "Recent advances in dye sensitized solar cells," Advances in Materials Science and Engineering, vol. 2014, Article ID 974782, 12 pages, 2014.

[13] A. Samimi, S. Zarinabadi, and M. Samimi, Solar energy application on environmental protection, International Journal of science and investigations, France, 2012.

[14] Ramesh, P. Nirmala, G. Ramkumar et al., "Simulation process of injection molding and optimization for automobile instrument parameter in embedded system," Advances in Materials Science and Engineering, vol. 2021, Article ID 9720297, 10 pages, 2021.

[15] A. H. N. Shirazi, F. Mohebbi, M. Azadi Kakavand, B. He, and T. Rabczuk, "Paraffin nanocomposites for heat management of lithium-ion batteries: a computational investigation," Journal of Nanomaterials, vol. 2016, 10 pages, 2016.

[16] F. O. Al Ghuol, K. Sopian, and S. Abdullah, "Enhancement of integrated solar collector with spherical capsules PCM affected by additive aluminum powder," Journal of Thermodynamics, vol. 2016, 7 pages, 2016.

[17] G. Peng, G. Dou, Y. Hu, Y. Sun, and Z. Chen, "Phase change material (PCM) microcapsules for thermal energy storage," Advances in Polymer Technology, vol. 2020, Article ID 9490873, 20 pages, 2020.

[18] F. S. Javadi, H. S. C. Metselaar, and P. Ganesan, "Performance improvement of solar thermal systems integrated with phase change materials (PCM), a review," Solar Energy, vol. 206, pp. 330-352, 2020.
[19] A. Ahmed, H. Baig, S. Sundaram, and T. K. Mallick, "Use of nanofluids in solar PV/thermal systems," International Journal of Photoenergy, vol. 2019, Article ID 8039129, 17 pages, 2019.

[20] G. Ramkumar, S. Sahoo, G. Anitha et al., “An unconventional approach for analyzing the mechanical properties of natural fiber composite using convolutional neural network," Advances in Materials Science and Engineering, vol. 2021, Article ID 5450935, 15 pages, 2021.

[21] I. R. Bellobono, F. Morazzoni, R. Bianchi et al., "Solar energy driven photocatalytic membrane modules for water reuse in agricultural and food industries. Pre-industrial experience using s-triazines as model molecules," International Journal of Photoenergy, vol. 7, no. 2, pp. 87-94, 2005.

[22] L. Coppola, D. Coffetti, and S. Lorenzi, "Cement-based renders manufactured with phase-change materials: applications and feasibility," Advances in Materials Science and Engineering, vol. 2016, Article ID 7254823, 6 pages, 2016. 